\title{
The Significance of Fathers for Inner-City African-American Teen Mothers
}

\author{
Letha A. Chadiha, Ph.D., and \\ Sandra K. Danziger, Ph.D.
}

ABSTRACT: Using the accounts of family life in young women's life stories, this qualitative study examined experiences with biological fathers for a sample of inner-city African-American teen mothers and a comparable sample of young women who were not parents. Distinguishing findings emerged about the pattern of young women's residential history with fathers, activity and interactions with fathers, and feelings about fathers. These qualitative findings were discussed in terms of their implications for services, policy, and research.

KEY WORDS: Adolescent Mothers; Biological Fathers; Family Life.

Adolescent birth rates have increased every year since 1987, after remaining rather stable or falling throughout the earlier decades. A recent report cites that there were 62 births to every 1000 women aged 15-19; one-fourth of African-American women had their first birth before they reached age 19 (Child Trends, 1994). High teen birth rates raise concerns about the well-being of adolescent mothers and their children. Children born to single teen mothers, particularly if they reside in inner-city communities, are likely to experience poverty,

We thank Julia Henly, Linwood Cousins, and Jen Rubin for assistance with data analysis; Carolyn Young and Oti-Lisa Brown for assistance with literature searches; Arlene Stiffman and Brett Drake for comments on an earlier draft of this manuscript. Generous support for this study was provided by the Ford Foundation, Spencer Foundation, Rockefeller Foundation and the University of Michigan Rackham Graduate School.

Dr. Chadiha is Assistant Professor at the George Warren Brown School of Social Work and Dr. Danziger is Associate Professor at the School of Social Work, University of Michigan. Address communications to Dr. Chadiha, Washington University, Campus Box 1196, One Brookings Drive, St. Louis, Missouri 63130-4899. 
receive public aid, and be at risk of poor educational and economic outcomes as they grow up. The daughters of teen mothers are at risk of repeating the pattern of becoming young single mothers before they complete their schooling (Miller \& Moore, 1990; Moore et al. 1993).

The barriers to the well-being of inner-city teen mothers and their children stem from a complex and multi-level array of factors. Within the family, the adolescent mother's lack of education, earnings and informal supports contribute to poor child outcomes; community-level deficits include the lack of employment opportunities, poor school quality in neighborhoods, and deteriorated housing conditions (Danziger \& Danziger, 1993). Lack of accessible services for primary health care also compromises child development (Klerman, 1991).

The literature on father involvement indicates positive paternal effects on children's well-being (Ishii-Kuntz, 1994; King, 1994; Levine, 1993). For example, a child's academic achievement in reading and math along with his or her own perceived scholastic achievement are associated with child support payments from nonresident fathers (King, 1994). Adopting King's view (1994), fathers may be out of the family household but not out of the lives of children, including adolescent mothers. Few studies have examined the perceptions of adolescent mothers about the role of biological fathers in adolescent mothers' family life. Consequently, very little is known about the influence of biological fathers on adolescent mothers' and their children's well-being. In studying adolescent motherhood, researchers have not adequately addressed how single childbearing might be related to a young woman's experiences with her own biological father. However, when family life is viewed through the embedded lens of the adolescent mother herself, a possibly different framework for understanding her behavior in relation to her own parenting may emerge.

In this qualitative study, we addressed the following questions. How do inner-city African-American teen women perceive the parenting they receive from their biological fathers? How do they evaluate the role of the biological father in their lives? From their feelings about their biological fathers, what can we extrapolate about the perceived role of men in family formation? We used the accounts of family life in young women's life stories to address these questions and understand how biological fathers were a potential resource to teen mothers and their children.

This qualitative article describes the range of father-daughter relationships available to a group of inner-city young women, both teen mothers and a comparison group of teens who have not given birth 
(non-parent peers). It examines their experience with respect to their parents' marriage, the teens' own residential history, and the degree of father involvement in their childhood and teenage lives. The article describes the range of feelings expressed toward biological fathers in life history accounts of the young women; it illustrates case examples that typify some major themes in young women's reports of family experiences with biological fathers. Building upon these qualitative data, we interpret the thematic findings as suggestive of how men's participation in family formation is more generally perceived. If parenting from fathers is viewed as a resource that has significant value for the young women in this study, service providers may need to adopt more inclusive strategies to bring fathers into the support systems of teen clients. The knowledge gained from studying teen mothers' perceptions of their biological fathers may serve to inform how much programs and policies serving adolescent mothers should advocate for and encourage father involvement.

\section{Overview of the Literature}

Almost 30 years ago, Nash (1965) asserted that psychologists ignored the father and denied him a significant position in the family. Twenty years later, Boyd (1985) wrote that until the 1970s researchers had emphasized the maternal role and overlooked the paternal role in family studies. Greif and Bailey (1990) concluded recently in a review of the literature that social work researchers have not adequately addressed fathers; they also asserted that fathers have been portrayed in a negative light. Although current studies portray fathers in a more positive way, such studies do not adequately address African-American adolescent mothers' biological fathers (e.g., Bowman, 1993; Pruett, 1993). The primary focus on African-American fathers has been their family provider role (Cazenave, 1979), nurturing role with young children (McAdoo, 1981), socialization of adolescent males (Allen, 1981), and their decision-making role in marriage (McAdoo, 1993).

Studies have revealed that adolescent mothers feel closer to their mothers than fathers and view fathers unfavorably (see review, Landy et al., 1983). Research has shown that pregnant and parenting adolescents report a low degree of paternal involvement and support. Pregnant teens in one study reported statistically significantly poorer relationships with their fathers than nonpregnant teens (Landy et al., 1983). According to this study, pregnant teens relative to nonpregnant teens also described their fathers in very negative 
terms and indicated that they hardly knew them. Anglo and Hispanic pregnant adolescents and young mothers in another study viewed their fathers as least supportive among family members, particularly when contrasted with the support received from their mothers (de Anda \& Becerra, 1984). The authors of this study concluded that the fathers of these adolescents held a very low profile in the adolescent's family network, exerted little influence, and provided little nurturing and support. Paternal involvement is associated with a more timely use of health services by pregnant adolescents in one study (Moss, 1987). Mexican, Mexican-American, and Anglo pregnant adolescents, in contact or living with their fathers, obtained pregnancy tests significantly earlier than those living apart from their fathers.

We have found only one study that addressed the perceptions of African-American teen mothers about biological fathers. Williams (1991) reports that a majority of African-American adolescent mothers in a qualitative study experienced father absence beginning in childhood. Most young women viewed their fathers unfavorably, and held bitterness toward them for their absence as well as lack of support (Williams, 1991).

This review provides a very unfavorable view of adolescent mothers' paternal experiences, and suggests that more research is needed. Most studies have not clarified whether biological fathers are being addressed. Neither have studies adequately addressed the topic of African-American adolescent mothers' biological fathers. A qualitative approach is very useful for addressing relatively unexplored research problems (Rosenblatt \& Fischer, 1993). Because of inadequate research on African-American teen mothers' fathers, we used a qualitative research approach to address the perceived role of biological fathers in family life.

\section{Study Method}

\section{Source of Data}

The 71 participants in this study were part of a larger pool of 80 young women interviewed about their family life and future options (e.g., upbringings and opportunities that contribute to perceived opportunities at various critical points of the life course) (Danziger, 1995; Danziger \& Farber, 1990). Participants in this larger pool formed a purposive sample of inner-city African-American young women, of whom 44 were adolescent mothers and 36 were nonmothers. They ranged in age from 14 to 21 at interview. These young 
women were recruited through contacts with staff in community agencies that provided youth services, such as teenage parent services, alternative schooling, and summer employment. Some of the non-mothers were recruited through peer contacts. For the current study, nine young women were dropped from the original sample: five adolescent mothers and two non-mothers over the age of 19 , one adopted adolescent mother, and one fostered adolescent mother. Thus the sample for this study includes 37 teen mothers and 34 nonmothers, who are 14 to 19 years old and not adopted or fostered.

The young women in this study resided in a large north-central U.S. city. They lived in neighborhoods characterized by poverty, unemployment, high drop-out rates from school, and crime. Except for school status, they were similar on their social background characteristics in most respects, as shown in Table 1 . Almost half of the young mothers in the current study were out of school at the time of the interview, which is consistent with studies highlighting school disruption effects of teen birth (Miller \& Moore, 1990; Moore et al., 1993). Their school disruption may be temporary, as studies suggest that many teen mothers finish high school or obtain a high school equivalency diploma (Moore et al., 1993; Upchurch, 1993). The nonparent teens were more likely to be in school or in programs to obtain their high school equivalency diploma. While the majority in both groups was over 16 years old, teen mothers were slightly more likely to be under age 17 than their non-parent peers.

In terms of family of origin (Table 1), more of the non-parent youth had currently married parents (almost one-fourth), whereas more of the teen mothers had unmarried parents (over two-fifths). Similar proportions of each group had separated or divorced parents. Living arrangements were thus similar, with the majority in each group residing with their mothers. Slightly more teen mothers resided with their partners or on their own than did the non-parent teens.

\section{Data Collection}

Using an in-depth life history interview, study participants were interviewed between January 1988 and August 1989, with a majority interviewed at two sessions within this period. All interviewers were women, including two researchers and three graduate students in social work and social science. With the permission of young women, we audio-taped their interviews. We addressed the issue of confidentiality by informing each young woman prior to her taped interview that information would not be released to agency staff. Interviews 


\section{TABLE 1}

\section{Background Characteristics on Teen Mothers and Non-Parents}

\begin{tabular}{|c|c|c|c|c|}
\hline & & $\begin{array}{l}\text { en } \\
\text { hers } \\
37)\end{array}$ & & $\begin{array}{l}\text { arent } \\
\text { ns } \\
34 \text { ) }\end{array}$ \\
\hline & & & & \\
\hline $14-16$ years old & 16 & $(42 \%)$ & 11 & $(32 \%)$ \\
\hline 17-19 years old & 21 & $(58 \%)$ & 23 & $(68 \%)$ \\
\hline School status & & & & \\
\hline In school & 14 & $(38 \%)$ & 22 & $(65 \%)$ \\
\hline In G.E.D. program ${ }^{a}$ & 4 & $(11 \%)$ & 10 & $(29 \%)$ \\
\hline Completed H.S. or G.E.D. & 1 & $(3 \%)$ & 2 & $(6 \%)$ \\
\hline Dropped out & 18 & $(49 \%)$ & 0 & \\
\hline Family of origin & & & & \\
\hline Parents married & 1 & $(3 \%)$ & 8 & $(24 \%)$ \\
\hline Divorced or separated & 14 & $(38 \%)$ & 16 & $(47 \%)$ \\
\hline Father has died & 5 & $(14 \%)$ & 2 & $(6 \%)$ \\
\hline Parents did not marry & 16 & $(43 \%)$ & 8 & $(24 \%)$ \\
\hline Missing & 1 & $(3 \%)$ & 0 & \\
\hline Living arrangement at interview & & & & \\
\hline With both parents & 1 & $(3 \%)$ & 7 & $(21 \%)$ \\
\hline With mother or grandparents & 23 & $(62 \%)$ & 18 & $(53 \%)$ \\
\hline With other relatives & 7 & $(19 \%)$ & 7 & $(21 \%)$ \\
\hline With non-relatives ${ }^{\mathrm{d}}$ & 4 & $(11 \%)$ & 2 & $(6 \%)$ \\
\hline Alone & 2 & $(5 \%)$ & 0 & \\
\hline
\end{tabular}

'G.E.D. means general equivalency diploma for completing high school.

"Some of these young mothers had plans to return to school, and may have had only short disruptions in schooling.

'One interview was only partially tape-recorded, resulting in less information.

${ }^{d}$ Non-relatives included boyfriends.

Note: Percentages in each category may not sum to $100 \%$, due to rounding error.

were conducted at an agency site in a private room. We interviewed a few participants in the privacy of their homes when it was not possible to arrange an interview at an agency site. We reimbursed young women $\$ 25$ for their participation in the study. Interviews ranged from 45 to 90 minutes per session and were transcribed verbatim. 


\section{Data Analysis}

We applied a qualitative coding technique for the identification of themes (i.e., recurring topics or ideas), as described in the work of Strauss (1987). The following procedures were used to analyze the life history interviews for content on young women's biological fathers. We read a subset of the transcripts and wrote detailed notes on content about fathers. From this initial reading and note taking, we then instructed four graduate social work students to code information about biological fathers from transcripts. We coded some transcripts two times in order to allow for a reliability check; this check coding was done by a different coder than the original coder. For each transcript, coders coded information about the marital history of young women's parents, young women's family composition, and their parental relationships.

This stage of the analysis, which we called extracting content units from the transcripts, was carefully monitored through discussion with coders and the application of certain objective standards in coding. For example, errors of omission were carefully controlled by having coders record page numbers and verbatim comments about fathers, parents' marital history, family's composition and parental relationships. These objective standards along with check coding a subset of the transcripts facilitated high internal consistency between coders.

\section{Themes of Father-Daughter Relations}

Of the many possible ways in which young women could describe the relationship they had with their biological fathers, three themes were most prominent. First, an important distinction in the pattern of residential history with the biological father occurred. Young women sometimes differentiated their paternal experiences in terms of when fathers were living with them as opposed to once fathers had left the home. For others, having never lived with their fathers was a critical feature of the paternal relationship, according to the young woman's perspective. On the basis of young women's reports, we observed three categories: (1) currently living with, (2) having ever lived with, and (3) having never lived with their biological fathers. We present a summary of these perceived living experiences in the top panel of Table 2. In terms of having ever lived with fathers, more of the nonparenting women were currently living with their fathers, whereas fairly similar and sizable proportions of both teen mothers (almost one-half) and non-parent teens (two-fifths) had previously lived with 
their fathers at earlier points in their lives. More of the teen mothers (over two-fifths) had never had the experience of living with their fathers at any time than did the non-parent teens (less than onethird).

A second theme in young women's descriptions of father-daughter relations was whether the type of activity or interaction occurred in more than one phase of the young woman's life. The reports of young women indicated how much their paternal experiences varied. For some teens, biological fathers were discussed as a more or less continuous part of their life history; these respondents talked about being taken care of by their fathers, going on outings with them, or being disciplined by them during both their earlier childhood and a more recent point in the teenage stage of life. For others, paternal interactions and relationship examples of biological fathers only referred to the past, when young women were "still young," which typically meant prior to adolescence. Some reports indicated biological fathers became involved in some teens' lives only later, during adolescence, after a rather dramatic emergence in their lives. Finally, the reports of some teens conveyed the lack of any substantive relationship across both life stages. For some of these young women, their biological fathers had been consistently absent throughout childhood and adolescence.

Descriptions of paternal involvement included social interactions (e.g., visitations), instruction and training, discipline, supervision, provision of economic resources and emotional support (see King, 1994). Some young women with non-resident biological fathers had maintained very close paternal ties, most of which were perceived in a positive light. Some young women who had lost contact with biological fathers perceived their fathers in a less positive light; the absence of fathers was often experienced as something missing in young women's lives and a more or less accepted fact of life than a negative feeling.

In describing positive paternal interactions, young women typically reported spending leisure time, talking, and visiting with their fathers. Young women's reports of positive paternal involvement were about mainly social interactions with fathers and less about disciplining and rule setting. A 15-year-old non-mother, who sees her father on weekends and holidays, commented: "I can go to him and talk about anything." A 16-year-old mother, who communicates regularly with her father in a different city and receives offers of help from him for her newborn, made these remarks: 
TABLE 2

\section{Perceptions of Father Involvement by Teen Mothers and Non-Parents}

\begin{tabular}{|c|c|c|c|c|}
\hline \multirow{2}{*}{ Ever lived w/father } & \multicolumn{2}{|c|}{$\begin{array}{c}\text { Teen } \\
\text { Mothers } \\
(n=37)\end{array}$} & \multicolumn{2}{|c|}{$\begin{array}{c}\text { Non-Parent } \\
\text { Teens } \\
(n=34)\end{array}$} \\
\hline & & & & \\
\hline Now & 2 & $(5 \%)$ & 10 & $(29 \%)$ \\
\hline Ever, but not now & 18 & $(49 \%)$ & 14 & $(41 \%)$ \\
\hline Never & 16 & $(43 \%)$ & 10 & $(29 \%)$ \\
\hline Missing & 1 & $(3 \%)$ & 0 & \\
\hline \multicolumn{5}{|l|}{ Reported activities with father } \\
\hline In childhood and adolescence & 13 & $(35 \%)$ & 21 & $(62 \%)$ \\
\hline In childhood only & 9 & $(24 \%)$ & 3 & $(9 \%)$ \\
\hline In adolescence only & 0 & & 4 & $(12 \%)$ \\
\hline Never & 15 & $(41 \%)$ & 6 & $(18 \%)$ \\
\hline \multicolumn{5}{|l|}{ Affective tone in describing father } \\
\hline Positive & 11 & $(29 \%)$ & 15 & $(44 \%)$ \\
\hline Negative & 17 & $(46 \%)$ & 12 & $(35 \%)$ \\
\hline Totally absent father, no affect & 9 & $(24 \%)$ & 7 & $(21 \%)$ \\
\hline
\end{tabular}

'One interview was only partially tape-recorded, resulting in less information.

Note: Percentages in each category may not sum to $100 \%$, due to rounding error.

So he'll call me, asks me how I'm doing ... So I talk to him and I used to not tell him my problems . . . but then I said 'that's your father, he do understand,' so I talk to him about problems, too. Matter of fact, I told him I was pregnant before I told my mother.

Other examples of positive paternal interactions include a 17-yearold mother whose father left when she was nine years old, but she sees him regularly and talks to him by telephone. When her father learned about her pregnancy, he suggested that she have it terminated because he wanted her to finish high school and attend college. A 15-year-old non-mother, who always lived with her father, talks to him about her grades. He wants her to finish high school. He coaches her softball games. A 17-year-old mother spoke about activities in the past with her deceased father in these words: 
My dad would take us to the zoo, parks and state fairs. He used to talk to me a lot. My parents (including her father) were strict, so I wasn't used to smoking cigarettes.

In terms of the timing in young women's lives when father-daughter relationships were experienced, the majority of non-parent teens reported having more continuity across the life course to date of interview (Table 2, second panel). Almost twice as many non-parent peers (three-fifths) as teen mothers (one-third) described activities they had done with their fathers during both childhood and adolescence. More teen mothers (almost one-fourth) talked about father-daughter interactions when they were young only, whereas for only non-parent teens, a few of the young women (over one-tenth) had fathers who became an active new participant during their adolescence. Many of the teen mothers (two-fifths) reported no experiences whatsoever of a father-daughter relationship, either during childhood or during more recent teen years.

The third theme that characterized daughter-father relationships was the emotional tone and feelings that the young women expressed in referring to their fathers (Table 2, panel 3). Adolescents expressed feelings about their biological fathers in different ways: either their affect was more positive than negative, more negative than positive, or there was no clear affect in their description, either positive or negative. Their affect occurred in some cases where fathers were present and in some cases where fathers were fairly consistently absent, or not at all a part of young women's lives. Some of the young women expressed hostile feelings about this absence, whereas others expressed neither negative nor positive feelings.

Teen mothers (almost one-half) perceived their fathers in a more negative light than did non-parents (over one-third) (Table 2). Negative feelings typically included resentment or derogatory descriptions. While more of the non-parenting youth expressed generally positive and loving, admiring feelings toward their fathers (under one-half compared to under one-third of teen mothers), a similar minority in both groups of young women were non-expressive of feelings or rather factual about their absent fathers (almost one-fourth of teen mothers and just over one-fifth of non-parent peers).

In describing positive feelings, the young women typically talked about the degree of emotional closeness they shared with their biological fathers, as suggested by the common phrase, "I am close to my dad." Or, they typically reported "We have a pretty good relationship." 
"My father understands me." "We get along." A 19 year-old mother of a divorced father commented:

My mother, we have a pretty good relationship. My father, too. It's pretty nice.

A 16-year-old mother commented:

I was my father's child. My mother and father were going through a divorce ... (Expressing concern over her father's illness) My father had a heart attack and I was just, you know, daddy's girl.

A 17-year-old non-mother, who had reunited and moved in with her divorced father and stepmother described in great detail the positive role he played in her life. With great pride, she described how he called her teachers at the alternative high school program and was personally invested in her schooling and future plans. Her high emotional attachment was clear from her comment:

If something was to happen to my dad any day, I don't think I could handle it. That's the closest person to me.

Some degree of lack of paternal involvement was expressed through negative tone in such terms as, "I don't see him." "He ain't never been around." "I see him, but we ain't got no relationship." "I haven't seen him but once (since he left) and that was around my seventh or eighth year." Some young women commented unfavorably through negative tone about their fathers' absence as well as nonsupport. An 18-year-old mother, for example, claiming no relationship with her absent father, gave this account: "My father ain't never been around ... never done nothing for $m \in$ in all his life. Never."

In contrast, one 18-year-old mother was not as negative in tone about her absent father. "Sue" had never had any father involvement, but only met him briefly for the first time at age 14 . He had left her mother when she was pregnant with Sue, but Sue described being "excited" about meeting him as a teen. Of her feelings, she said, "I wasn't going to condemn him because he might give me the love I need." No further involvement in her life was noted beyond this meeting, but her feelings suggested that his absence left an important void.

A more elaborate and involved re-emergence of the father in a teen's life was described by a 16-year-old non-parent, "Sandra," who 
was raised mostly by her mother's godparents. She first came into contact with her father at age 11 or 12 . Having married someone else shortly after Sandra was born, he was not in her life because her mother did not want "anything from him." Besides Sandra, he had other children and had been married twice. The circumstances by which she came to meet him were described as follows:

My mother wanted me to know my father before I got up and grown and didn't know anything about him. So, she would try to talk to him and say, "well, at least call her, I'm not asking you for nothing else, but just talk to her sometimes!" And, as I got older, I got in touch with him and I just told him, I said, "well, I don't want anything from you; I just would like for you to contact me every now and then, just to see how I am doing there. Or, you know, even on my birthdays, just wish me Happy Birthday. That's enough." And so, it is getting a little bit better now; but every once in a while he'll start slipping. I have to tell him.

There are other ways she describes the efforts to develop this relationship:

My grandmother told him, "you going to mess around and she's going to get grown and then she's not even going to want to be bothered with you and then you're going to be talking about, oh, my daughter, oh my daughter ... " I mean I can't make him call me or anything, so he has to do it on his own. But I will let him know I would like to have a father and daughter relationship with him, but if I don't, I won't. I'm soon to be 16 and if he hadn't started it yet, I don't think he will ever get started.

When asked if she could change one thing in her life, Sandra responded by saying she wished her mother and father were married. She is "close" with one of her stepbrothers, a son of her father, and they both wish they had the same mother and that they could all be together with their father. While Sandra's extensive efforts to engage her father in her life and those of her mother and grandmother are met with resistance and unresponsiveness, other young women had given up on this relationship and were more openly critical of not just their fathers, but of other men more generally. Two examples of teen mothers typify this connection between having strong negative feelings about their own fathers' absence and having low hopes that other men will be extensively involved in family life.

"Nellie" described her father's behavior when she was age two and again at age seven or eight as trying to make her choose between living with him or her mother who had re-married. She felt she could not trust any men after these experiences. 
I don't trust boys; they are liars and users; it was the same way with my daddy. My daddy left my mother when I was two and one half ... There ain't no males nowhere that I like. I am going to be my son's role model and teach him right from wrong.

In a different part of her interview, Nellie emphasized that she left her boyfriend, wanting him to have no part of her baby's life. Part of her rationale for his irrelevance was that he had little capacity to be a positive force; his own father had walked out on his mother when he was a baby.

In the case of "Pat," we have interview data from sessions conducted before the baby was born and at the point when she called him a "toddler." In the interim, her father had died, and as a result she was receiving a survivor's pension. In the first interview, Pat described being close with her grandparents with whom she had lived rather continuously. She mentioned only agitated family life with her mother. She had made no mention of her father until asked, "What about your dad, Pat?" She replied, "Oh, my dad . . I d don't associate with him ..."

Yet, Pat has future plans to go into the military like her dad did, suggesting some degree of relevance for his role in her future life. The parallel irrelevance of her baby's father for her family is indicated by the change in his role over the two interviews. She described her boyfriend in the earlier stages of the relationship as involved in discussing and using birth control and helping her to decide what to do about the pregnancy. For example, after they had become sexually active, he seemed to advocate using birth control so she could stay in school. When she took the pills incorrectly and became pregnant, he at first advocated that she get an abortion. She felt that was against her family's beliefs, and that she was responsible enough to have this baby. They talked about schooling and decided it would "be no problem" for her to return to school and repeat 11 th grade and complete her last year of school after she had the baby. She summed up his view by saying, "he came around."

However, Pat's boyfriend was not physically around, but was away at college in another town throughout the later stages of the pregnancy, birth, and at the later interview. They wrote letters and saw each other on vacations while she was still pregnant. Her talk of her future after the baby was born did not make any mention of him. Instead, she had hopes of finishing school, going to college, getting a job to support herself and her baby, getting a house and a car, and then buying a house for her grandmother. 
By the second interview, while Pat was adjusting to having a ninemonth-old "toddler," she mentioned having a new male friend. When asked about the baby's father, she remarked:

To me, he don't even have to come see him, because I figure I'm the mother, the father, the grandmother, the aunt, the uncle. Hey, I'm the best friend, whatever, daddy, whatever. I don't even, see we got this understanding and he just like a best friend. You know it don't even seem like he the baby's daddy because he is so far away ... We talk, we see each other . . . because he in college I don't fault him for that, for wanting to go to college. . . . I don't pressure nobody to do something that they don't want to. . . I can't tell his feelings . . . I knew how he felt at one time but times have changed because it has been so long.

\section{Discussion}

Very little research has been done on the perceptions of AfricanAmerican teen mothers about the role of biological fathers in family life. To sum up the findings of this study, both inner-city teen mothers and non-parents experience positive and negative relationships with their fathers. Thus, young mothers are not different from non-parent peers in having only negative experiences or total absence of involvement with their biological fathers. Many young women in both groups have resided with their fathers at least in childhood. Yet adolescent mothers experience more discontinuity in living arrangements and less involvement with their fathers than do non-parents in this study. While both groups include young women who have never had a relationship with their father, this was more common for young mothers. Although quite a few teen mothers report no activities or contact with fathers, about equal numbers of both groups of young women express no affect about the lack of a relationship. More non-parent peers have had overall more positive and involved relationships with their fathers. These relationships across types of residential history with fathers have significance for the young women.

Findings on the residential history of adolescent women in this qualitative study are consonant with survey research findings on African-American family structure. Survey research findings indicate single mother families now constitute more than half of AfricanAmerican families (Hunter \& Ensminger, 1992; Jarrett, 1994). Given prior evidence, it is no surprise that young women report much father absence in the current study.

Reports of father absence and discontinuity in having a father- 
daughter relationship are more frequent among the adolescent mothers than non-mothers. This is consistent with survey studies (Miller \& Moore, 1990). Reports of activity and interactions with biological fathers in childhood and adolescence in the current study, however, defy an image of adolescent mothers' complete detachment and isolation from their fathers. The accounts in these data suggest some degree of emotional attachment and connectedness to nonresident biological fathers. This sometimes results in a pattern of flexible living arrangements. The flexible living arrangement of some young women with nonresident fathers resembles what Stack (1982) calls "elasticity of residence" in poor single mother families. Stack interprets the flexible living arrangement of children in poor families as an alternative way of coping with adverse economic circumstances. For both groups of young women in this study, their flexible living arrangements may enhance rather than prohibit the maintenance of family ties with fathers over time.

Prior research suggests that African-American adolescent mothers perceive their fathers in a more negative than positive light (Williams, 1991). This study finds that adolescent mothers report both favorable and unfavorable views of biological fathers. Young women's reports of father-daughter interactions in the current study underscore the nurturing role of African-American fathers (McAdoo, 1993). On the other hand, young women report little about their fathers' provider role.

We have raised the further question of how these perceptions of fathers might be related to the young women's views about men in family life more generally. Men appear in some young women's family life accounts as extraneous, non-essential, or minimally involved. That is, adolescent mothers' biological fathers and their babies' fathers are perceived to play marginal roles in the family life of these young mothers and their children. Non-resident fathers are perceived with a sense of loss in spite of their absence.

This qualitative study must be considered as a preliminary examination of the role of biological fathers in adolescent mothers' family life. Nonetheless, study findings raise concerns about the exclusion of biological fathers from current research, policy, and practice with adolescent mothers. Teen mothers in this study view their biological fathers as a resource for emotional and instrumental support; this has promise for targeting fathers as participants in the service delivery system of adolescent mothers.

Both teen mothers and non-parents report positively about family 
experiences with biological fathers-whether in the home or not. This suggests that young women in the current study perceive their fathers as an important part of their family collective unit. It further suggests that service providers who fail to recognize the deep significance of adolescent mothers' paternal experience may be underestimating and overlooking a potential resource to young mothers and their children. The conflicting relationships or negative feelings that adolescent mothers communicate may require practitioners to assess the relative costs and benefits of greater paternal involvement. In this regard, practitioners should be alerted to adolescent mothers' unfavorable reports of dissociation and disaffection from their fathers. The negative, positive, and more neutral feelings that young women report about their fathers may be relevant to their own family formation experiences.

This study's findings on the significance of fathers in adolescent mothers' family life should direct practitioners to advocate for a more inclusive role of biological fathers. If young women felt entitled to their fathers and could expect their fathers' involvement, this could possibly have positive outcomes for young women's well-being. That is, including fathers in adolescent mothers' lives might increase overall amounts of familial support that would facilitate completion of schooling. The inclusion of biological fathers might convey that the children of adolescent mothers also have the right to responsible and engaged fathers. By helping to enlarge the presence of fathers in teen mothers' lives, this might increase the teens' demand for accountability from their babies' fathers. If children are viewed as mutually obliging of both parents, then younger female and male siblings in these families might feel differently about taking the risk of parenthood when they reach adolescence.

The developmental literature on adolescence indicates that paternal relationships are important to a young woman's development in terms of her own self-identity and heterosexual relationships (Rice, 1992). Prior research has established a relationship between the characteristics of the adolescent mother's mother and the adolescent's own sexual behavior (Miller \& Moore, 1990). The extent to which paternal relationships or lack of such relationships influence African-American adolescent mothers' self-identity as well as heterosexual relationships is a topic for future research to address.

The associations with biological fathers raised in these data merit future exploration. Adolescent mothers' sense of men as minimally involved in everyday family life may be important for inculcating a 
sense of options and responsibility for parenting and childbearing. Future research ought to consider the broader implications of the range of paternal experiences identified in this study. Researchers should also broaden the definition of father to include the views of daughters about other father figures. This study does not address perceptions of stepfathers; however, it is of interest that some young women expressed similar ranges of experiences with their stepfathers.

\section{References}

Allen, W. R. (1981). Moms, dads, and boys: Race and sex differences in the socialization of male children. In L. E. Gary (Ed.), Black men (pp. 99-114). Beverly Hills: Sage Publications.

Bowman, T. (1993). The father-son project. Families in Society, 74, 22-27.

Boyd, S. T. (1985). Study of the father. American Behavioral Scientist, 29, 112-128.

Cazenave, N. A. (1979). Middle-income black fathers: An analysis of the provider role. The Family Coordinator, 28, 583-593.

Child Trends, Inc. (1994, March). Facts at a glance. Washington, D.C.

Danziger, S.K. (1995, forthcoming). Family life and teenage pregnancy in the innercity: Experiences of African-American youth. Children and Youth Services Review, $17(1-2)$.

Danziger, S. K., \& Danziger, S. (1993). Child poverty and public policy: Toward a comprehensive antipoverty agenda. Daedalus, 122, 57-84.

Danziger, S. K., \& Farber, N. B. (1990). Keeping inner-city youths in school: Critical experiences of young black women. Social Work Research \& Abstracts, 26, 32-39.

de Anda, D., \& Becerra, R. M. (1984). Support networks for adolescent mothers. Social Casework, 65, 172-181.

Greif, G. L., \& Bailey, C. (1990). Where are the fathers in social work literature? Families in Society, 71, 88-92.

Hunter, A. G., \& Ensminger, M. E. (1992). Diversity and fluidity in children's living arrangements: Family transitions in an urban Afro-American community. Journal of Marriage and the Family, 54, 418-426.

Ishii-Kuntz, M. (1994). Paternal involvement and perception toward fathers' roles: a comparison between Japan and the United States. Journal of Family Issues, 15, 30-48.

Jarrett, R. L. (1994). Living poor: Family life among single parent, African-American women. Social Problems, 41, 30-49.

Klerman, L. (1991). Alive and well? A research and policy review of health programs for poor young children. New York: National Center for Children in Poverty.

King, V. (1994). Nonresident father involvement and child-well being: Can dads make a difference? Journal of Family Issues, 15, 78-96.

Landy, S., Schubert, J., Cleland, J. F., Clark, C., \& Montgomery, J. S. (1983). Teenage pregnancy: Family syndrome? Adolescence, 18, 679-694.

Levine, J. A. (1993). Involving fathers in Head Start: A framework for public policy and program development. Families in Society, 74, 4-21.

McAdoo, J. L. (1981). Black fathers and child interaction. In L. E. Gary (Ed.), Black men (pp. 115-130). Beverly Hills: Sage Publications.

McAdoo, J. L. (1993). The roles of African-American fathers: An ecological perspective. Families in Society, 74, 28-35. 
Miller, B. C., \& Moore, K. A. (1990). Adolescent sexual behavior, pregnancy and parenting: Research through the 1980s. Journal of Marriage and the Family, 52, 1025-1044.

Moore, K. A., Meyers, D. E., Morrison, D. R., Nord, C. W., Brown, B., \& Edmonston, B. (1993). Age at first childbirth and later poverty. Journal of Research on Adolescence, $3,393-422$.

Moss, N. E. (1987). Effects of father-daughter contact on use of pregnancy services by Mexican, Mexican-American, and Anglo adolescents. Journal of Adolescent Health Care, 8, 419-425.

Nash, J. (1965). The father in contemporary culture and current psychological literature. Child Development, 36, 261-297.

Pruett, K. D. (1993). The paternal presence. Families in Society, 74, 46-50.

Rice, F. P. (1992). The adolescent: Development, relationships, and culture. Boston: Allyn \& Bacon.

Rosenblatt, P. C., \& Fischer, L. R. (1993). Qualitative family research. In P. G. Boss, W. J. Doherty, R. LaRossa, W. R. Schumm, \& S. K. Steinmetz (Eds.), Sourcebook of family methods: A contextual approach (pp. 167-177). New York: Plenum Press.

Stack, C. B. (1982). All our kin. New York: Harper \& Row, Publishers.

Strauss, A. (1987). Qualitative analysis for social scientists. Cambridge: Cambridge University Press.

Upchurch, D. M. (1993). Early schooling and childbearing experiences: Implications for post secondary school attendance. Journal of Research on Adolescence, 3, 423-443.

Williams, C. W. (1991). Black teenage mothers: Pregnancy and child rearing from their perspective. Lexington, MA: Lexington Books. 